\title{
Sorption properties of materials based on residual biomass
}

\author{
Yulia Smyatskaya ${ }^{1, *}$, Arina Kosheleva ${ }^{2}$, and Elena Taranovskaya ${ }^{3}$ \\ ${ }^{1}$ Peter the Great St.Petersburg Polytechnic University, Russia \\ ${ }^{2}$ Hamburg University of Technology (TUHH), Germany \\ 3Orenburg State University, Russia
}

\begin{abstract}
In this paper, we consider the possibility of using inexpensive and effective sorption materials based on plant raw materials, such as fruit rind, vegetable waste, fallen leaves, and the use of phytosorbents for the purification of sewage containing heavy metals and petroleum products. The use of vegetable waste for the manufacture of sorbents is a priority for solving environmental problems. It is suggested to use residual biomass as a sorption material, which is formed after extraction of lipids from $\mathrm{C}$. sorokiniana microalgae and duckweed Lemna minor. To increase the sorption capacity, it was proposed to thermally modify the residual biomass. The optimum heat treatment conditions were $450{ }^{\circ} \mathrm{C}$ for 20 minutes with limited access to oxygen. The obtained biomass allows one to extract ions of heavy metals with efficiency of $91-93 \%$ for ions of lead, cadmium, zinc and copper.

To increase the sorption capacity ( $\mathrm{A}, \mathrm{mg} / \mathrm{g}$ ) of the residual biomass, heat treated waste from the agro-industrial complex and chitosan were proposed as additives. The addition of chitosan makes it possible to obtain a sorption material in the form of granules, which is convenient to use. For the sorption materials obtained, microstructural studies were carried out, which allowed us to substantiate the sorption properties of the materials. The physical and mechanical properties of sorbents, such as abrasion, grindability, allow us to offer new materials for use on an industrial scale. In the article, a technological scheme for obtaining sorption materials from residual biomass is given.
\end{abstract}

\section{Introduction}

Microalgae are intensively used in various branches of the national economy, for example as additives for livestock, materials for biologically active additives, phytosorbents for wastewater purification and so on [1-5]. It is known from literature that microalgae biomass contains cellulose as the major component (23.5\%), starch, hemicelluloses, chitin- and pectine-like substances. Containing of cellulose, hemicellulose and chitin substances determine sorption properties of biomass, so usage of algae for water purification is advantageous [6].

${ }^{*}$ Corresponding author: smyatskaya_yua@spbstu.ru 
It is known that C. sorokiniana, C. vulgaris and S. obliquus microalgae are used as sorbents for purification of wastewaters from pharmaceutical production. The investigations on removal of paracetamol, acetylsalicylic acid and diclofenac from wastewaters were carried out. The most efficient removal of paracetamol was obtained using the C. sorokiniana strain [7]. The paper [8] presents consideration of C. sorokiniana microalga as a biosorbent for heavy metals. Influence of $\mathrm{pH}$ value on removal of heavymetal ions (HMI) was studied. It was shown that the higher $\mathrm{pH}$ was, the more negative charge the cell wall got and more easily the positively charged metal cations penetrated. C. sorokiniana showed the highest efficiency of lead ions removal from wastewater in comparison with other metals. Due to large ion radius it is the easiest to embed into the cell wall.

Also it is important to note the work [9], in which C. vilgaris was used to purify waters from organic colorants. Preliminary the cells were modified using the ferromagnetic liquid, stabilized by chloric acid. Treatment by this composition resulted in tight connection of algae cell walls with nanoparticles of iron oxide of 10-12 nm diameter. In such a way modified cells could be easily extracted from solution after colorants sorption by a strong constant magnet.

In the work [10] cells of C. Sorokiniana were immobilized on a sponge of loofah for removal the chromium ions. Sponge of loofah was preliminary prepared by boiling in distilled water with further washing out. Microalgae implantation was carried out within 24 days. Further the samples were used for chromium ions removal from model solutions. Efficiency of chromium (III) ions removal was $98 \%$, sorption capacity was $69.9 \mathrm{mg} / \mathrm{g}$. The possibility of its multiple usage (not less than 5 cycles) was proved. Due to convenience of usage the problem of industrial usage of sorbent was solved.

Also the processes for sorption of chromium (III) using the green algae were studied. In the work [11] metal sorption was carried out using the specially prepared granules of some $\mathrm{mm}$ diameters, which consisted of polymer base and included in it powder of C. vulgaris or S. Acutus.

For its obtaining polyvinyl alcohol and sodium alginate were dissolved in boiling water. Further the mixture was cooled up to $40{ }^{\circ} \mathrm{C}$ and powder from algae was added. Solution of monomers and microalgae was drop by drop added to the saturated solution of boric acid and 2\%-solution of calcium chloride, which was intermixed with 600-700 rpm. Addition of calcium chloride provides high porosity of granules due to damage of bonds between natrium and alginate. Immobilization process occured for 2 hours. Further the granules were collected and quickly washed for removal of residual boric acid. The granules were put into a $2 \mathrm{M}$ solution of sodium orthophosphate for 5 hours at room temperature at constant intermixing for hardening. Phosphorylated and hardened spheres were filtered, washed under water and left up to the room temperature to eliminate a part of its moisture. Then they were storaged in plastic container in fridge at $4{ }^{\circ} \mathrm{C}$. Statistical analysis did't show any significant difference in efficiency of chromium (III) sorbtion by granules with powder of various algae.

In the recent years much attention is payed at usage of inexpensive adsorbents from plant wastes for removal $\mathrm{Cu}$ (II) and $\mathrm{Zn}$ (II) from polluted water. The work [12] presents consideration of falling leaves as sorbent. For removal toxic metals from industrial waters one use waste which is produced at sugar production [13, 14]. Lignin-containing wastes based on fruit and vegetable peels at certain modification possess rather high sorption properties [15, 16], usage of pomelo peel is considered in [17]. There are examples of usage of Egyptian mandarin [18], fruit juice residue [19], garlic peel and mercerized garlic peel [20], citrus fruits [21], muskmelon peel [22], pomegranate [23], rice straw [24].

The aim of this work was to study sorption properties of residual biomass of Chlorella microalgae, which is formed after lipids obtaining. 


\section{Materials and methods}

As an object under study we used residual biomass of Chlorella microalgae, after lipids obtaining and waste from the agro-industrial complex - sunflower, barkey, buckwheat and millet husk.

For obtaining thermally-treated wastes in laboratory condition a special hermetical form was created from steel. Its diameter is $5 \mathrm{~cm}$, height is $2 \mathrm{~cm}$, displacement volume $\mathrm{V}=39$ $\mathrm{cm}^{3}$. In this form, which allow one to limit oxygen supply from air to eliminate burning of organic component we carried out synthesis of sorption materials in the Snol muffle furnace for 20 minutes.

For obtaining granules based on chitosan, thermally-treated residual biomass (TTB) and thermally-treated wastes from the agro-industrial complex (TTWA) we prepared mixture of the following composition: $40 \mathrm{~g}$ of chitosan is added to $960 \mathrm{~g}$ of $3 \%$ acetic acid. It is stirred for about 4-5 hours until chitosan is completely dissolved. After this TTB and (or) TTWA are added. Then the obtained jellous mixture is dropwise added through a syringe in a $5 \%$ $\mathrm{NaOH}$ solution. The resulting granules are kept in alkali solution $(\mathrm{NaOH})$ for 24-hour period and after that they are rinsed in water to get $\mathrm{pH}$ 7.0-7.5. Granules are dryed at room temperature [25-26].

Sorption materials of the following composition were produced:

Sample №1 - $100 \mathrm{ml}$ of chitosan, $5 \mathrm{~g}$ of thermally-treated residual biomass;

Sample №2 - $100 \mathrm{ml}$ of chitosan, $5 \mathrm{~g}$ of thermally-treated residual biomass, $5 \mathrm{~g}$ of thermally-treated wastes of agriculture.

The residual concentration of heavy metal ions was determined by voltammetric method (PND F 14.1:2:4.222-06) using the TA-Lab device. The inaccuracy of measuring technique was $25 \%$. For experimental investigation sorption was held for 20 minutes, calculated as 20 $\mathrm{g}$ of sorption material for $1 \mathrm{l}$ of model solution, containing heavy metal ions (zinc, cadmium, lead, copper). The mixture was intermixed using the laboratory shaker.

For calculation the sorption capacity we prepared model solutions with concentration 1 $\mathrm{g} / \mathrm{l}$. Sorption capacity was calculated as a difference between initial and equilibrium concentrations taking into account sorbent mass and solution volume.

Derivatographic analysis was carried out using the thermogravimetric analyzer TGA/DSC1. Operating temperature ranges were from room temperature to $1600{ }^{\circ} \mathrm{C}$. Heating rates were from 0.01 to $250{ }^{\circ} \mathrm{C} / \mathrm{min}$.

Abrasion and grindability were measured according to the established technique. For this purpose the sorbent samples were carefully washed out by distilled water, dried at 105$110{ }^{\circ} \mathrm{C}$ up to the constant mass. Mass was considered to be constant when the difference between 2 subsequent weighting after drying within 30 minutes do not exceed $1 \mathrm{mg}$. They were separately sieved at sieves № 2.0 and № 0.5. Samplings of the material which passed sieve № 2.0 and rested on the sieve № 0.5 of $100 \mathrm{~g}$ each were placed in 5 glass tubes of 250 $\mathrm{cm}^{3}$ volumes with caps and $150 \mathrm{~cm} 3$ of distilled water was added in each one. The tubes were tightly closed with caps and placed for 24 hours in a shaker. After finishing shaking the tube content was transferred into porcelain dishes, evaporated water and dried at 105$110{ }^{\circ} \mathrm{C}$ up to the constant mass. The dried material samplings were subsequently sieved though sieves № 0.5 and № 0.25 . Mass of the material (g) which passed sieve № 0.5 and rested on the sieve № 0.25 characterized the material grindability and was expressed in percent volume ratio of total material sampling mass. Mass of the material $(\mathrm{g})$ which passed sieve № 0.25 characterized the material abrasion and was expressed in percent volume ratio of total material sampling mass.

The microstructure investigations were carried out using the microscope of passing and reflected light "Axio Imager.A2m". 


\section{Results and Discussion}

To determine optimum conditions of thermal treatment of the residual biomass we carried out thermogravimetric analysis (Figure 1), which showed that the treatment should be performed within temperature range from 200 to $500{ }^{\circ} \mathrm{C}$.

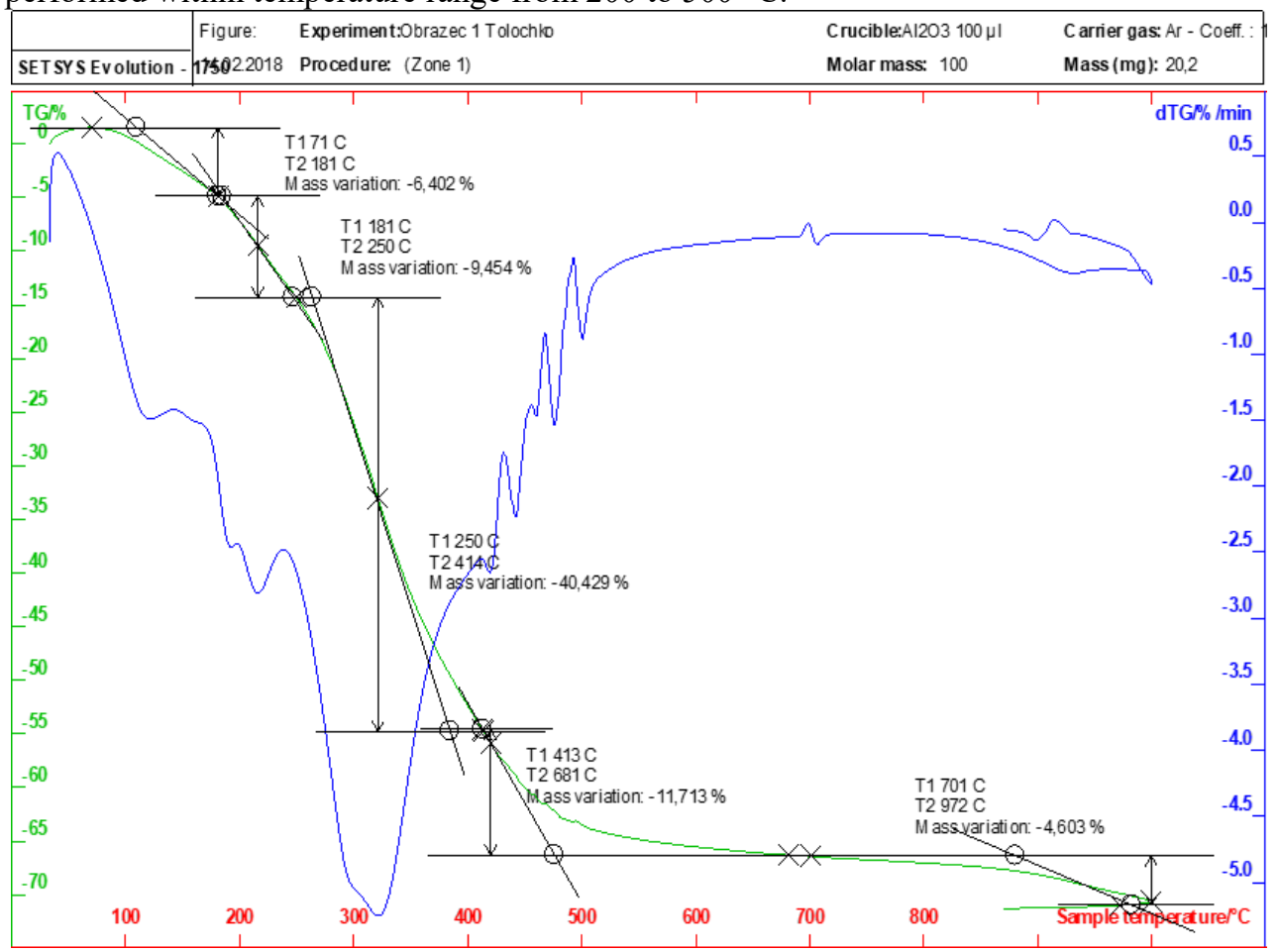

Fig. 1. Thermogravimetric analysis of the residual biomass

For obtaining thermally-treated residual biomass and waste from the agro-industrial complex in laboratory condition a special hermetical form was created from steel, in which the coking processes were performed. In order to investigate adsorption properties of the thermally-treated residual biomass it was added in the amount of $20 \mathrm{~g} / \mathrm{l}$ to the model solutions of concentration $20 \mathrm{mg} / \mathrm{l}$, which contained ions of zinc, cadmium, lead and copper. Sorption time was 20 minutes (Table 1). It is seen from Table 1 that thermal treatment of residual biomass at temperature $4500 \mathrm{C}$ allows us to significantly improve sorption capacity for heavy metal ions, purification efficiency is $91-93 \%$.

Table 1. Efficiency of purification the model solutions from HMI by residual biomass before and after thermal treatment

\begin{tabular}{|c|c|c|c|c|}
\hline \multirow{2}{*}{ Temperature, ${ }^{\circ} \mathrm{C}$} & \multicolumn{4}{|c|}{ Purification efficiency, \% } \\
\cline { 2 - 5 } & Zinc & Cadmium & Lead & Copper \\
\hline Initial & 28 & 69 & 47 & 28 \\
\hline 200 & 32 & 72 & 72 & 69 \\
\hline 300 & 77 & 73 & 80 & 75 \\
\hline 400 & 81 & 83 & 81 & 90 \\
\hline 450 & 92 & 93 & 92 & 91 \\
\hline 500 & 92 & 93 & 92 & 91 \\
\hline
\end{tabular}


To enhance the sorption capacity (A, $\mathrm{mg} / \mathrm{g}$ ) and improve physical-mechanical properties of sorption material we propose to produce granules which are bonded by chitosan, obtained at OOO "Chitosanovye technologii", which meet Specifications TU 9289-06700472124-03.

For the obtained samples №1 and №2 the maximum sorption capacity was determined and physical-mechanical properties of granules were investigated (Table 2). It is seen from Table 2 that sorption capacity in increased for 3-5\%, and physical-mechanical properties meet the Russian State Standard GOST R 51641-2000.

Table 2. Sorption and physical-chemical properties of sorption materials based on chitosan

\begin{tabular}{|l|c|c|c|c|c|}
\hline \multirow{2}{*}{$\begin{array}{c}\text { Type of } \\
\text { Sorption material }\end{array}$} & \multicolumn{3}{|c|}{$\mathrm{A}, \mathrm{mg} / \mathrm{gr}$} & Abrasion, \\
\cline { 2 - 4 } & $\mathrm{Pb}^{2+}$ & $\mathrm{Cd}^{2+}$ & $\mathrm{Zn}^{2+}$ & $\begin{array}{c}\text { Grindability, } \\
\%\end{array}$ \\
\hline Residual biomass & 82.8 & 74.4 & 80.7 & - & - \\
\hline Sample 1 & 323.5 & 319.0 & 323.7 & 0.3 & 2 \\
\hline Sample 2 & 435.3 & 390.5 & 444.0 & 0.4 & 3 \\
\hline $\begin{array}{l}\text { Russian State Standard } \\
\text { GOST R 51641-2000. }\end{array}$ & - & - & - & 0.5 & 4 \\
\hline
\end{tabular}

Microstructure investigations have shown that composite material from residual biomass and chitosan possess porous structure (Figure 2, a). At addition of thermallytreated waste from the agro-industrial complex the layered structure preserves (Figure 2, b), It proves possibility of physical adsorption of heavy metal ions.

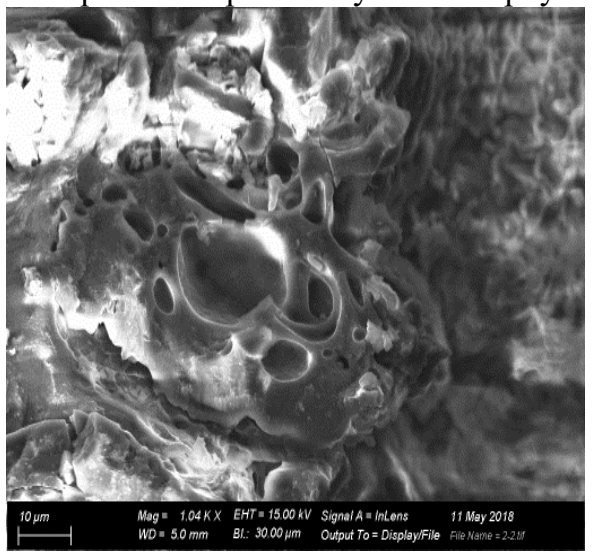

a

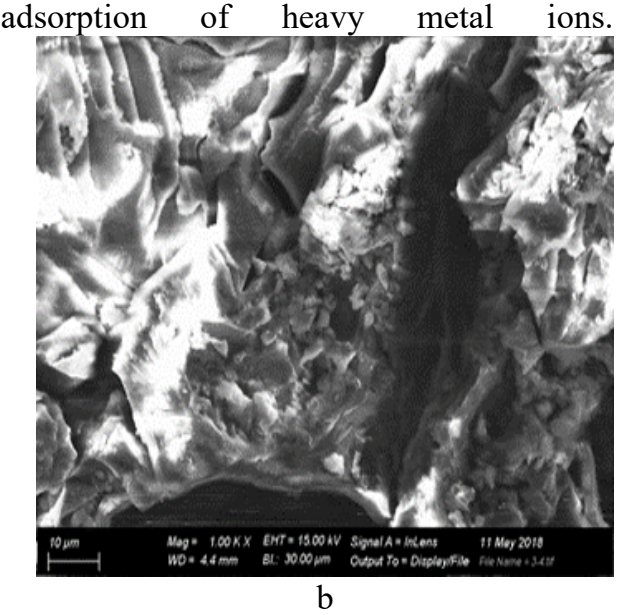

Fig. 2. Surface morphology of sample №1 (a) and sample №2 (b)

For obtaining granules from residual biomass and chitosan we developed a principle technological scheme presented in Figure 3. From storage container for chitosan 3 using the dosing vessel 4 it is transferred to mixing unit 5 in amount required for obtaining $6 \%$ solution of acetic acid. Simultaneously $3 \%$ solution of acetic acid from storage container 7 is poured into the mixing unit 5 using the dosing vessel 6 . In mixing unit 5 the mixture of chitosan and acetic acid is formed at constant intermixing for 24 hours. Preliminary from container 1 residual biomass or waste from the agro-industrial complex are transferred to the furnace 2, where they are thermally treated. Using dosing vessel 4 the residual biomass and waste from the agro-industrial complex are transferred into the mixing unit 5 with solution of chitosan in acetic acid and is intermixed for 1 hour. The obtained mixture using the dosing unit 8 is drop by drop added to the granules' precipitation chamber, which is filled by $5 \%$ solution of $\mathrm{NaOH}$, which is transferred from container 9 using the dosing 
vessel 10. In granules' precipitation chamber 11 the black granules are formed. For granules washing out water from tank 18 is used. After washing out water is transferred to alkali tank 9 up to achievement $\mathrm{pH}=7-7.5$. Measuring of $\mathrm{pH}$ values is performed using the $\mathrm{pH}$ meter 19 .

To separate the obtained granules from the solution the mesh filter is used, which is produced of inert material (stainless steel, chemically-stable polymers) 12 with mesh dimensions less than granules sizes $(1-2 \mathrm{~mm})$. Filter with obtained granules is moved into the drying cupboard 14 and is dried for 4 hours. For air purification from alkali vapour the absorber 15 is used. For providing permanency of the granules-obtaining process 2 mesh filters 12 and 13 are used, which replace one another. After total drying the granules are strewed into the storage container 16. Carbonized biomass from container 17 using the dosing vessel is packed.

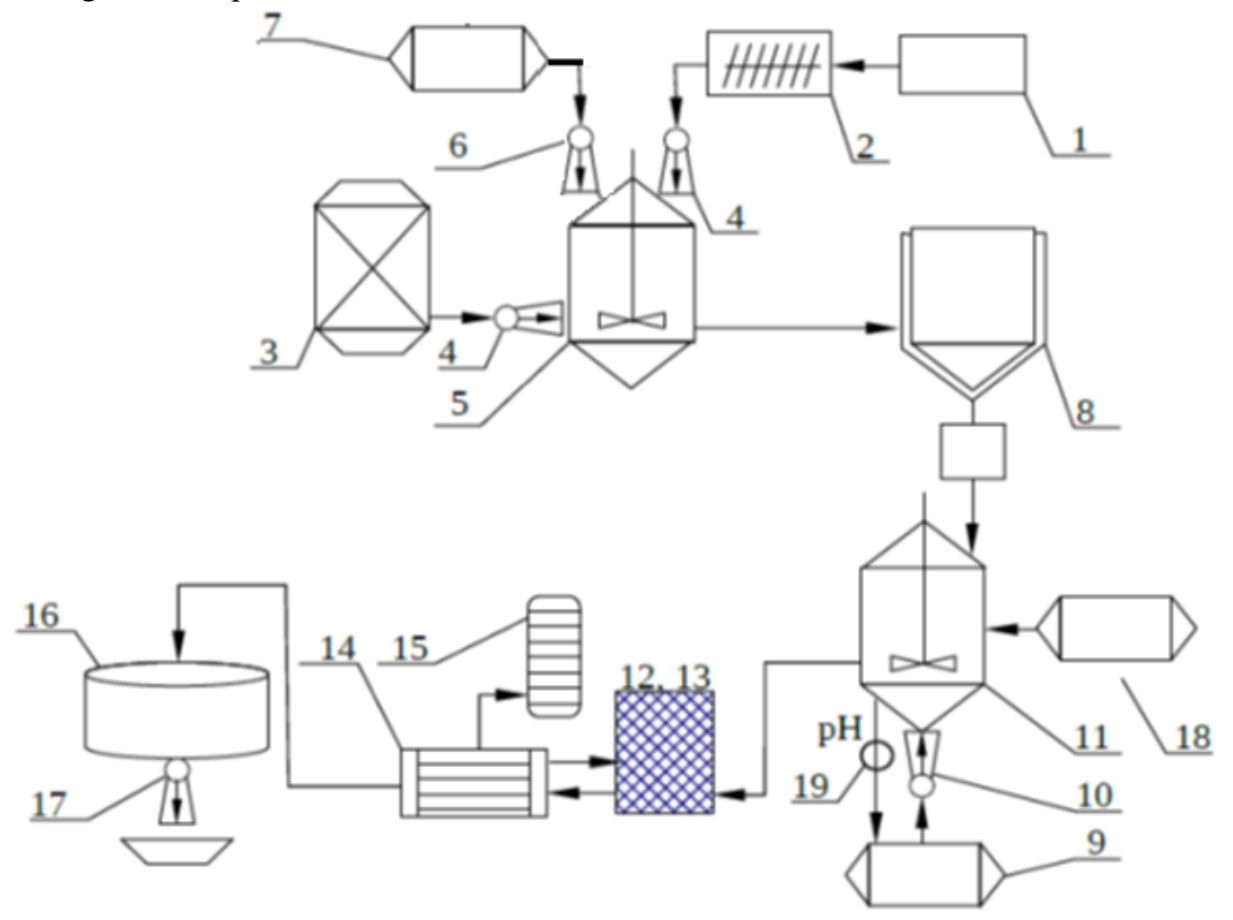

Fig. 3. The scheme for obtaing granulated sorbents: 1 - storage container for residual biomass; 2 furnace for thermal treatment of residual biomass and waste from the agro-industrial complex ; 3 storage container for chitosan; 4 - dosing vessel for chitosan; 5 - mixing unit; 6 - dosing vessel of acetic acid; 7 - storage container for acetic acid; 8 - dosing unit; 9 - storage container for alkali; 10 dosing vessel of alkali; 11 - granules' precipitation chamber; 12,13 - mesh filters; 14 - drying cupboard; 15 - absorber; 16 - storage container for granules; 17 - dosing unit for the obtained granules; 18 - tank with water; 19 - $\mathrm{pH}$-meter

For utilization the obtained materials from wastewater purification one uses the scheme presented in Figure 4. 


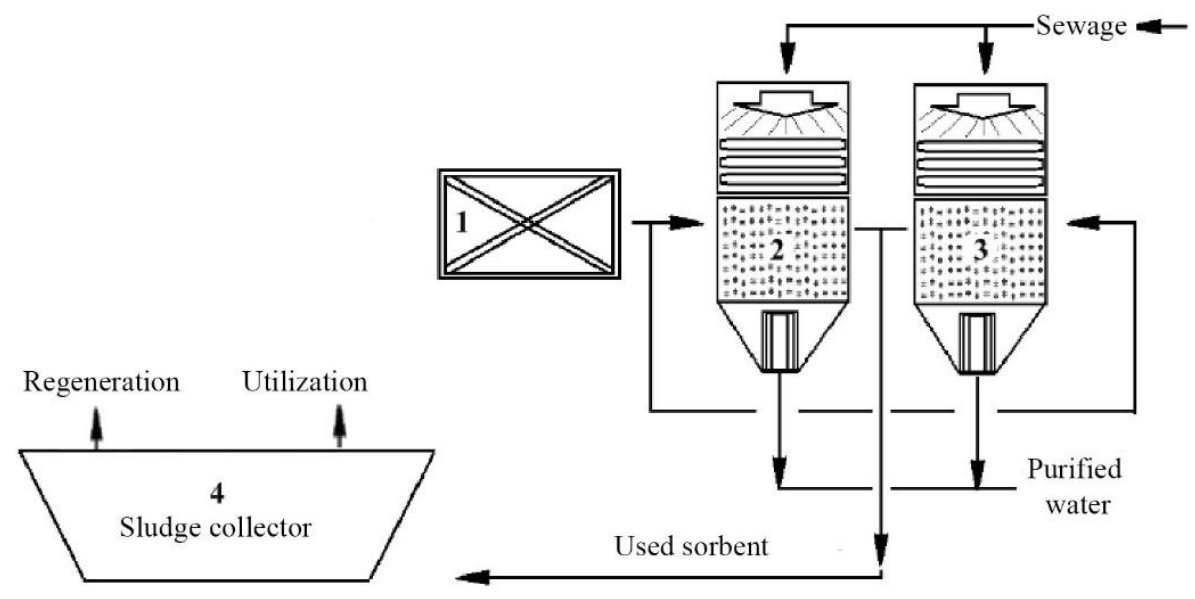

Fig. 4. Schematic diagram for usage granulated sorbents: 1 - Storage container for granules; 2,3 Adsorbents; 4 - Sludge collector

The granules are poured from the storage container 1 to adsorbents 2 and 3 (after reaching maximum sorption capacity by granules the water flow is turned to the parallel adsorber), where wastewater purification takes place. The used sorption material is transferred to sludge collector 4 , from which it is directed to the subsequent utilization.

The calculation of economical indicators for production of granulated sorbent in the amount of 15 tons annually was carried out. It has shown that manufacturer's price for granulated material was 118.5 rubles $/ \mathrm{kg}$. Capital expenses for production granulated sorbent were 383,320 rubles and will be repaid in 1 year, and capital expenses for production granules based on chitosan, residual biomass and waste from the agro-industrial complex were 867,027 rubles and its payback period will be 2 years.

\section{Conclusions}

1. It was proposed to use residual biomass as a sorbent for wastewater purification from heavy metal ions. Optimum conditions for thermal treatment were selected, which appeared to be $4500 \mathrm{C}$ for 20 minutes.

2. To increase sorption capacity and improve physical-chemical properties it was proposed to add chitosan and carbonized waste from the agro-industrial complex. The obtained samples possess the sorption capacity up to $444.0 \mathrm{mg} / \mathrm{g}$ for zinc ions.

3. The microstructure investigations of the granulated sorbents surfaces are presented, which state for the samples' porous and layered structure.

4. A technological scheme for production granulated sorption materials based on residual biomass with chitosan and carbonized waste from the agro-industrial complex is proposed.

5. A schematic diagram for utilization of granulated sorbents is described.

\section{References}

1. N. Politaeva, Y. Smyatskaya, A. Toumi , A. Oparina, Eurasian Chemico-Technological Journal 20(3), 243-247 (2018) 
2. A. Asadpoori, C. Ankomah, A. Asadpoori, O. Derevianko, E. Shaburov, MATEC Web of Conferences 193, 02039 (2018)

3. N. Politaeva, T. Kuznetsova, Y. Smyatskaya, I. Atamaniuk, E. Trukhina, Advances in Intelligent Systems and Computing 692, 555-562 (2018)

4. N. Politaeva, Y. Smyatskaya, V. Slugin, A. Toumi, M. Bouabdelli, IOP Conference Series: Earth and Environmental Science 115(1), 012001 (2018)

5. E.S. Zalata, Y.Y. Shavrov, K.I. Strelets, M.S. Emelyanova, Magazine of Civil Engineering 81(5), 43-51 (2018)

6. H. G. Gerken, B. Donohoe, E. P. Knoshaug, Planta 237, 239-253 (2013)

7. C. Escapa, R. N. Coimbra, S. Paniagua, A. I. García, M. Otero, Journal of Applied Phycology 29, 1179-1193 (2017)

8. S. Liang et al., Polish Journal of Environmental Studies 26, 1139-1146 (2017)

9. M. Safarikova, B. M. R. Pona, E. Mosiniewicz-Szablewska, F. Weyda, I. Safarik, Fresenius Environmental Bulletin 17, 486-492 (2008)

10. N. AKHTAR, M. IQBAL, S. I. ZAFAR, J. IQBAL, Journal of Environmental Sciences 20, 231-239 (2008)

11. L. Ardila, IOP Conference Series: Earth and Environmental Science 83, 1-16 (2017)

12. Jagruti N. Jadava, Sandip D. Maindb and Satish A. Bhaleraoa, Octa Journal of Environmental Research 3(1), 067-079 (2015)

13. O. Karnitz et al., Bioresource Technology 98, 1291-1297 (2007)

14. A. Kumar, World Journal of Chemical Education 1, 17-20 (2013)

15. A. Bhatnagar, M. Sillanpää, A. Witek-Krowiak, Chemical Engineering Journal 270, 244-271 (2015)

16. Abdolali, W.S. Guo, H.H. Ngo, S.S. Chen, N.C. Nguyen, K.L. Tung, Bioresour. Technol. 160, 57-66 (2015)

17. P.Tasaso, Clean Energy Technol. 2, 154-157, (2014)

18. D. Z. Husein, Desalination and Water Treatment 51, 6761-6769 (2013)

19. D. Yadav, M. Kapur, P. Kumar, M. K. Mondal, Process Safety and Environmental Protection 94, 402-409 (2015).

20. W. Liu et al., Environmental Science and Pollution Research 21, 2054-2063 (2014)

21. R. Saha et al., Research on Chemical Intermediates 39, 2245-2257 (2013)

22. K.Huang, H.Zhu, Environ. Sci. Pol lut. Res. 20, 4424-4434 (2013)

23. M. Moghadam, N. Nasirizadeh, Z. Dashti, E. Babanezhad, Int. J. Ind. Chem. 4, 1-6 (2013)

24. A. Khalil, N. Sergeevich, V. Borisova, Adsorption Science and Technology 36(5-6), 1294-1309 (2018)

25. N.A. Politaeva, V.V. Slugin, E.A. Taranovskaya, I.N. Alferov, M.A. Soloviev, A.M. Zakharevich, Proceedings of the higher educational institutions. ENERGY SECTOR PROBLEMS 60 (7), 85-90 (2017)

26. E.A. Taranovskaya, N.A. Sobgaida, D.V. Markina, Chemical and Petroleum Engineering 1, 1-5 (2016). 